\title{
Role of Radical Cystectomy in Non-Organ Confined Bladder Cancer: A Systematic Review
}

\author{
Roger Li, Michael Metcalfe, Janet Kukreja and Neema Navai* \\ Department of Urology, The University of Texas MD Anderson Cancer Center, Houston, TX, USA
}

\begin{abstract}
.
Background: Currently, a diagnosis of non-organ confined bladder cancer (NOCBCa) confers a grave prognosis. The mainstay of treatment consists of systemic chemotherapy. However, it must be recognized that NOCBCa is a heterogeneous disease state with important clinical distinctions. While surgical extirpation has traditionally been regarded as overly aggressive for all NOCBCa patients, its utility as part of a multimodal treatment strategy in various clinical scenarios has not been thoroughly investigated.

Objective: To perform a review of the literature regarding the role of radical cystectomy and pelvic lymph node dissection (RC-LND) in the setting of NOCBCa.

Methods: Medline, and Pubmed electronic database were queried for English language articles from January 1990 to Nov 2016 on RC-LND for cT4, lymph node positive, and metastatic urothelial cancer. NOCBCa was separated into four distinct clinical scenarios: 1 . Locally advanced/unresectable disease (cT4bNOM0); 2 . Occult pelvic nodal disease (pN+) (cTxN0M0 and pTxN1-3Mx); 3. Clinical node positive disease (cN+) (cTxN1-3M0); and 4. Distant metastatic disease (TxNxM1). Evidence for the role of RC-LND in each of these clinical scenarios was summarized.

Results: cT4b may be more effectively treated by presurgical chemotherapy (PSC) than other forms of NOCBCa. Although clinical response predicted improved survival, surgical factors, such as surgical margin status may also play a role in determining outcomes. In well selected patients, 5-year CSS may reach 60\% after consolidative RC-LND. Survival in patients found to have pathologic nodal metastases without PSC was dictated not only by the histologically verified metastatic nodal disease burden, but also by the meticulousness of the lymph node dissection. In these patients, adjuvant chemotherapy may improve survival. On the other hand, in patients undergoing RC-LND after PSC, pathologic complete response (pCR) was the strongest predictor of improved CSS. The results of population based studies have suggested a therapeutic role by consolidative RC-LND in both patients with $\mathrm{cN}+$ and metastatic $\mathrm{BCa}(\mathrm{mBCa})$. For the $\mathrm{cN}+$ population, 5 -year $\mathrm{OS}$ was $31 \%$ in patients undergoing RC-LND after PSC vs. 14\% in those receiving chemotherapy alone. Similarly, consolidative intensive local therapy improved OS by approximately 5 months in patients with $\mathrm{mBCa}$. Metastasectomy has also been shown to be effective in small retrospective series and may especially be useful in patients with solitary pulmonary lesions.

Conclusions: Extirpative treatment of the primary tumor may be an important step in the management of de novo NOCBCa. The current retrospective and population based studies have demonstrated improved survival outcomes in patients with NOCBCa following RC-LND, especially in those with favorable response to PSC. With the advent of minimally invasive surgery and the enhanced post-surgical recovery protocols, RC-LND has not only been demonstrated to be feasible, but also tolerable in the setting of advanced $\mathrm{BCa}$. Well designed, prospective trials are needed to definitively assess the value of surgical extirpation for NOCBCa patients.
\end{abstract}

Keywords: Radical cystectomy, non-organ confined bladder cancer, metastatic bladder cancer

\footnotetext{
*Correspondence to: Neema Navai, Department of Urology The University of Texas MD Anderson Cancer Center, 1515 Hol-
}

combe Blvd, Unit 1373 Houston, TX 77030, USA. Tel.: +1 713 794 4824; E-mail: nnavai@mdanderson.org. 


\section{ABBREVIATIONS}

\begin{tabular}{|c|c|}
\hline $\begin{array}{l}\text { NOCBCa } \\
\text { RC-LND }\end{array}$ & $\begin{array}{l}\text { Non-organ confined bladder cancer } \\
\text { radical cystectomy and pelvic lymph } \\
\text { node dissection }\end{array}$ \\
\hline PSC & presurgical chemotherapy \\
\hline CSS & cancer specific survival \\
\hline pCR & pathologic complete response \\
\hline $\mathrm{BCa}$ & bladder cancer \\
\hline $\mathrm{mBCa}$ & metastatic bladder cancer \\
\hline OS & overall survival \\
\hline RFS & recurrence free survival \\
\hline AJCC & $\begin{array}{l}\text { American Joint Committee on Cancer } \\
\text { classification }\end{array}$ \\
\hline MIBC & muscle invasive bladder cancer \\
\hline TURBT & transurethral resection of bladder tumor \\
\hline EUA & exam under anesthesia \\
\hline LN & lymph node \\
\hline ERAS & enhanced recovery after surgery \\
\hline NMIBC & non-muscle invasive bladder cancer \\
\hline LND & lymph node density \\
\hline CR & complete response \\
\hline UTUC & upper tract urothelial carcinoma \\
\hline LT & local treatment \\
\hline RARC & robotic-assisted radical cystectomy \\
\hline
\end{tabular}

\section{INTRODUCTION}

Recently, local extirpative surgery has been increasingly integrated into the multimodal approach to metastatic disease arising from a wide range of solid tumors [1-3]. In theory, local treatment can be beneficial in three ways: 1 . Eradicate residual disease after favorable response to presurgical systemic therapy; 2. Minimize disease burden and improving the response to adjuvant systemic therapy; 3 . Palliate symptoms related to locally advanced disease. Specifically for $\mathrm{BCa}$, high incidence of relapse has been demonstrated at chemo-sensitive sites of disease, emphasizing the importance of consolidative surgical extirpation [4]. Along these lines, RC-LND may lead to improved RFS and OS in patients with metastatic bladder cancer ( $\mathrm{mBCa}$ ).

Albeit the gold standard for organ-confined $\mathrm{BCa}$ [5], RC-LND is associated with high perioperative morbidity. Mean length of hospital stay after RCLND ranges between 9-11 days [6, 7], with high complication $(58-77 \%)$ and readmission $(27 \%)$ rates even at high-volume centers [8-10]. Hence, RCLND could only be utilized selectively, especially in the elderly and frail population afflicted by $\mathrm{mBCa}$.
Additionally, a complex array of clinical scenarios exist in NOCBCa, making the interpretation of existing data difficult. Finally, recent updates in the American Joint Committee on Cancer (AJCC) classification downgrading common iliac nodal disease from M1 to N3 status made many previous studies obsolete [11]. In this review, we aim to systematically analyze the existing data on RC-LND performed in four different clinical scenarios of NOCBCa as illustrated by four index patients: 1. Locally advanced/unresectable disease (cT4bNOM0); 2. Occult pelvic nodal disease (pN+) (cTxN0M0 and pTxN1-3Mx); 3. Clinical node positive disease $(\mathrm{cN}+)(\mathrm{cTxN1}-3 \mathrm{M} 0)$; and 4. Distant metastatic disease (TxNxM1) (Fig. 1).

\section{CURRENT MANAGEMENT}

Cisplatin-based combination chemotherapy has been the standard-of-care for NOCBCa since the late 1980's [12]. Despite clear survival benefits, life expectancy after treatment remains poor. For instance, $\mathrm{OS}$ in $\mathrm{mBCa}$ patients after chemotherapy range between 12.5-14.8 months [12-14]. Prognosis is especially poor after post-chemotherapy relapse, with median OS falling short of 8 months [15]. Although recent advances in immunotherapy have offered hope to many $\mathrm{mBCa}$ patients failing cisplatinbased chemotherapy, objective response rates remain relatively low (between 15-21\%) [16]. Despite their modest response rates, as of this writing, five immune checkpoint blockade agents have been approved by the FDA, with two also showing efficacy as first-line agents in the cisplatin ineligible population [16].

Due to the relative lack of evidence demonstrating benefit of local control, RC-LND has not been incorporated into treatment guidelines for NOCBCa in its current iteration [5]. Consequently, local disease progression may lead to symptoms such as intractable hematuria and obstructive uropathy, severely compromising quality of life and requiring repeated invasive palliative procedures $[17,18]$.

\section{THE IMPACT OF IMPERFECT CLINICAL STAGING}

The management of MIBC has been undercut by the lack of accurate staging tools [19]. Clinical tumor staging consists of clinical and pathologic findings on TURBT and examination under anesthesia (EUA), while cross-sectional imaging is relied upon for the 


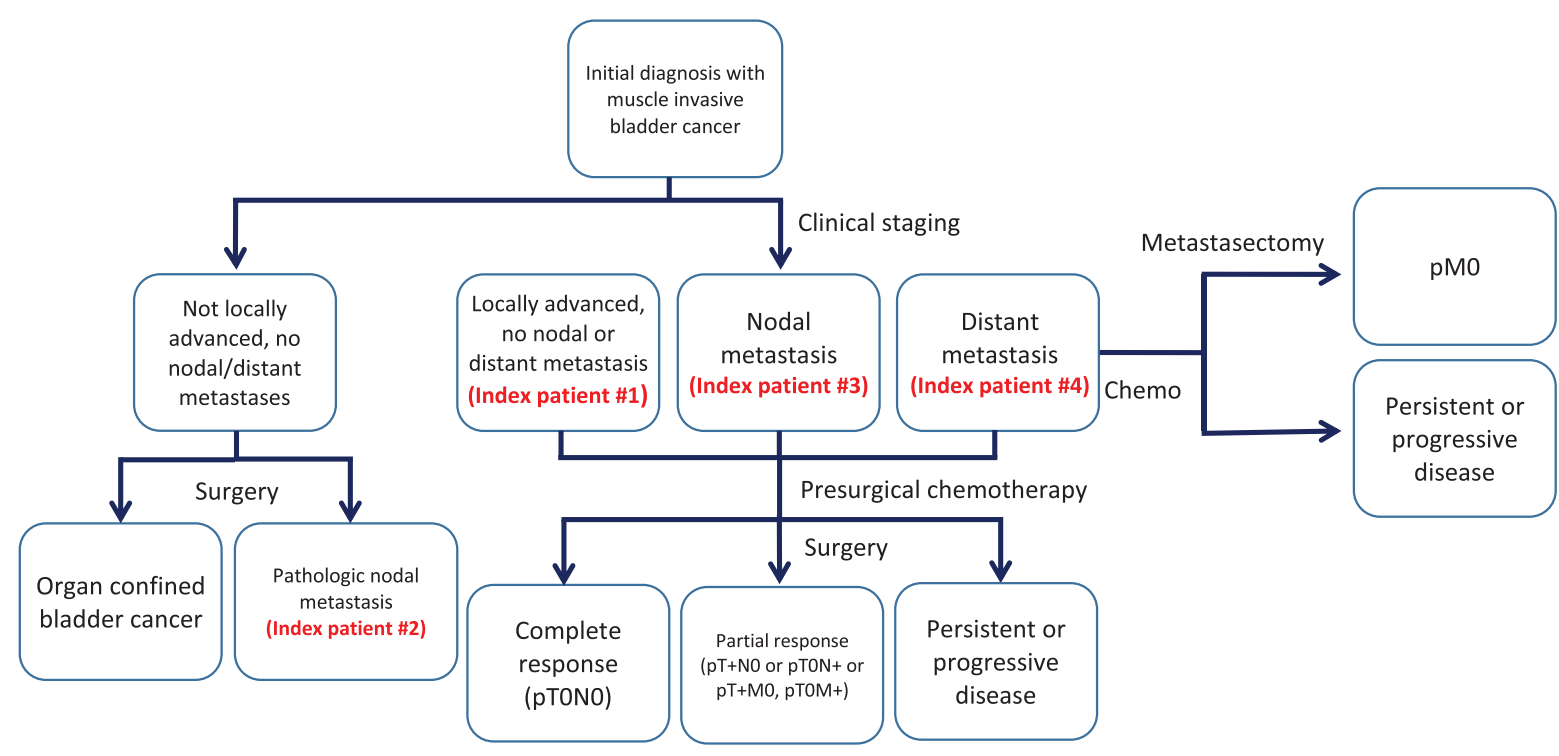

Fig. 1. Flow diagram of patient categories and method of therapy.

detection of perivesical, nodal and metastatic spread. Although CT urography has been the most widely used imaging modality, its accuracies for staging both the primary tumor as well as metastatic disease remain woefully inadequate. In evaluating the primary tumor, CT is unable to distinguish between Ta to T3a tumors [20]. Moreover, as assessment of nodal metastases by $\mathrm{CT}$ is based solely on size. As a result, poor sensitivity $(31 \%)$ results from its inability to detect small-sized nodal metastases [21]. Despite offering enhanced soft tissue visualization, MRI only yielded incrementally improved accuracies of $63 \%$ compared to $56 \%$ by CT [22]. In practice, the incidence of occult nodal metastases was found to be as high as $40 \%$ in patients with high clinical risk features [23].

Ultimately, inaccurate clinical staging can lead to both unintended overtreatment in patients with occult metastatic and/or locally advanced disease and undertreatment in patients with pseudometastatic disease. To recapitulate the clinical conundrum resulting from the imperfect clinical staging tools, two index patients with lymph node (LN) metastases were created. Index patient 2 represents clinical understaging. To understand the role of surgical extirpation in this setting, data from historical surgical series without the use of PSC were analyzed. On the other hand, index patient 3 represents the common clinical scenario with $\mathrm{cN}+$ disease. In interpreting the results of $\mathrm{cN}+$ series, the readers must be reminded that many of the included studies did not require histologic proof of nodal metastases prior to treatment. Thus, improved outcomes may reflect inclusion of patients with false positive clinical nodal metastases.

\section{INDEX PATIENT 1: CT4B DISEASE IN THE ABSENCE OF DISTANT DISEASE}

Prior to analyzing the existing literature on the efficacy of RC-LND for T4b BCa, the important distinction between cT4b and pT4b must be emphasized. cT4b BCa is defined by fixation on EUA after TURBT and/or evidence of direct invasion of an adjacent organ (other than prostate, vagina, or uterus) on cross sectional imaging [19]. On the other hand, pT4b BCa represents direct invasion of the abdominal/pelvic wall on histologic examination of the RC-LND specimen. While many studies have documented the futility of extirpative surgery in treating pT4b BCa [24-26], few have assessed the efficacy of a multimodal approach incorporating RC-LND to cT4b BCa.

That cT4b BCa may be more effectively treated by cisplatin-based chemotherapy followed by surgery than other forms of metastatic BCa was first suggested by Fossa et al. [27]. In this study, observed response rate to chemotherapy in $\mathrm{cT} 4 \mathrm{~b} \mathrm{BCa}$ patients was $57 \%$, with $28 \%$ achieving CR. Moreover, 5year OS was $25 \%$ in these patients, higher than those achieved in others with LN, lung or other sites of metastases. Even without the aid of robotic surgical technology and the modern day ERAS pro- 
Table 1

$\mathrm{pN}+$ disease without presurgical chemotherapy

\begin{tabular}{|c|c|c|c|c|c|c|}
\hline Study (year) & $\begin{array}{c}\text { Number of } \\
\text { patients }\end{array}$ & $\begin{array}{l}\% \text { of RC- } \\
\text { LND } \\
\text { patients }\end{array}$ & Follow up & Survival & $\begin{array}{l}\text { \# of positive } \\
\text { nodes } \\
\text { predicting } \\
\text { survival } \\
\end{array}$ & Comments \\
\hline Lerner (1993) & 132 & $22 \%$ & 5.5 yrs (2.6-18.8 yrs) & $\begin{array}{l}\text { Median PFS } 1.5 \text { rys, } \\
5 \text { yr OS } 29 \%\end{array}$ & 6 & $\begin{array}{l}\text { pT3b associated with increased } \\
\text { risk of progression and death }\end{array}$ \\
\hline Aprikian (1995) & 25 & $21.6 \%$ & $2.2 \mathrm{yrs}(0.6-8.7 \mathrm{yrs})$ & $\begin{array}{l}\text { Median OS } 2.3 \text { yrs, } \\
3 \text { yr OS } 33 \%\end{array}$ & - & \\
\hline Vieweg (1999) & 193 & $25.3 \%$ & $7.7 \mathrm{yrs}$ & $\begin{array}{l}\text { Median OS } \sim 2 \text { yrs, } \\
\text { 5yr OS } 31.2 \%\end{array}$ & - & \\
\hline Mills (2001) & 83 & $18 \%$ & - & $\begin{array}{l}\text { Median OS } 1.7 \text { yrs, } \\
5 \text { yrs OS } 29 \%\end{array}$ & 5 & $\begin{array}{l}\text { Lymph node capsule perforation } \\
\text { and diameter }>0.5 \mathrm{~cm} \\
\text { associated with increased } \\
\text { mortality }\end{array}$ \\
\hline Stein (2003) & 244 & $23 \%$ & $>10$ yrs $(0-28$ yrs $)$ & 5 yrs RFS $35 \%$ & 8 & $\begin{array}{l}\text { Extravesical primary tumor and } \\
15 \text { or less removed lymph } \\
\text { nodes conferred higher } \\
\text { recurrece }\end{array}$ \\
\hline Frank (2003) & 154 & - & $4.5 \mathrm{yrs}(0.1-13.9 \mathrm{yrs})$ & $\begin{array}{l}\text { Median CSS } 4.5 \text { yrs, } \\
5 \text { yr CSS } 39.4 \%\end{array}$ & 5 & $\begin{array}{l}\text { Adjuvant chemo and number of } \\
\text { positive LN's associated with } \\
\text { CSS }\end{array}$ \\
\hline Madersbacher (2003) & 124 & $24 \%$ & 3.8 yrs $(0.1-14.7 \mathrm{yrs})$ & $5 \mathrm{yr}$ OS $26 \%$ & - & Adjuvant chemo improved OS \\
\hline
\end{tabular}

tocol, consolidative RC-LND was rendered to 28 of 245 patients with cT4b or pelvic nodal metastases. Subsequently, Herr et al. further strengthened the case for post-chemotherapy surgery by demonstrating $41 \%$ OS in patients achieving CR by way of multimodal treatment [28]. However, due to the small cohorts, neither study identified favorable prognostic indicators in cT4b patients receiving combination chemotherapy/RC-LND.

To date, Black et al. performed the only study specifically examining the pathologic features and survival in cT4b patients undergoing RC-LND. In 23 patients, $30 \%$ were found to have $\mathrm{pT} 4 \mathrm{BCa}$, while $26 \%$ were downstaged to NMIBC. Although only 3 patients were found to have a positive surgical margin, this did confer a poorer CSS (HR 5.3; 95\% CI: $1.25-22.8, p=0.024)$. In addition, pathologic nodal metastasis also predicted poorer CSS (HR 29.3; 95\% CI: $3.1-275, p=0.003)$. Remarkably, 5-year CSS in this group was $60 \%$ [29]. Although limited by the small cohort size, results of this study suggested that RC-LND can be efficacious in a select group of patients with cT4b BCa.

\section{INDEX PATIENT 2: OCCULT NODE POSITIVE DISEASE}

Skinner was the first to demonstrate that long term survival was attainable in some $\mathrm{BCa}$ patients with nodal metastases following surgical resection [30]. Thereafter, many small retrospective series demon- strated 5-year postoperative survival ranging from 29-39.4\% [31-35] (Table 1). In the two largest series to date, 10-year RFS was $34 \%$ per Stein et al. [6] and CSS was $16.7 \%$ per Hautmann et al. [36]. However, the survival benefit specifically derived from RC-LND is difficult to assess.

Incident in 18-24\% of all patients undergoing RCLND without PSC [6, 36, 37], pN+ BCa garnered much attention and many studies were performed to identify prognosticators for postsurgical survival. Early on, many recognized that even in patients with $\mathrm{pN}+\mathrm{BCa}$, pathologic $\mathrm{T}$ staging continued to play an important role [35, 38]. In his analysis of 244 patients with $\mathrm{pN}+\mathrm{BCa}$, Stein et al. found 10-year RFS to be $44 \%$ in patients with organ confined $\mathrm{BCa}$ compared to $30 \%$ in those with extravesical extension $(p=0.003)$ [38].

Similarly, high LN disease burden was found to portend poor survival [31-35, 38]. Whereas early reports differentiated survival based on $\mathrm{N}$ staging [31, 35], others found cutoffs in the number of metastatic LNs to be prognostic for short survival $[6,32-34$, 38 ]. For example, Stein et al. found patients with more than 8 nodal metastases having a dismal 10 -year RFS of $10 \%$, compared to $40 \%$ in those with lighter metastatic burden [38]. In another study consisting of $154 \mathrm{pN}+\mathrm{BCa}$ patients, the optimal threshold for prognosticating CSS was found to be 5 [32], corroborating many previous reports $[6,33,34]$. In addition, the number of LNs retrieved during surgical resection was also found to be prognostic [38-40]. In a sec- 
ondary analysis of the data from SWOG 8710, Herr et al. pinpointed $10 \mathrm{LNs}$ as the minimum requirement for conferring higher RFS and OS in pN0 and $\mathrm{pN} 1$ patients [41]. Incorporating both the number of metastatic LNs and LNs retrieved, Stein et al. coined the term lymph node density (LND) and found a cutoff of $20 \%$ having prognostic value for RFS $(43 \%$ 10 -year RFS if LND <20\% vs. 17\% 10-year RFS if LND $>20 \%, p<0.001)$. The prognostic value of LND was subsequently confirmed independently, albeit at a slightly different value of $25 \%$ [42]. Other features of nodal metastases shown to be relevant to OS include extracapsular extension and nodal metastasis diameter $>0.5 \mathrm{~cm}$ [34].

In addition to the nodal yield, template of node dissection had also been shown to impact survival. In an inter-institutional study comparing a limited nodal dissection template (encompassing the area on the pelvic sidewall between the genitofemoral nerve laterally, the obturator nerve medially, bifurcation of the common iliac vessels proximally and the circumflex iliac vessels distally) to an extended template (additionally encompassing tissue adjacent to the common iliac vessels caudad to the ureteral crossing and medial and lateral to the internal iliac vessels), 5-year RFS post extended LND was found to be superior in $\mathrm{pN}+$ patients (35\% vs. $7 \%$ ) [43]. However, a subsequent study failed to find survival benefit in patients undergoing superextended LND, which also included retroperitoneal nodes below the inferior mesenteric artery [44].

The implication on survival due to nodal metastases found over the common iliac vessels had been a historical point of contention. The 6th edition of the AJCC staging system defined these nodes as metastatic disease (M1), suggesting significantly worse outcomes compared to patients with regional nodal disease within the true pelvis. However, a review by Steven and Poulsen revealed that 5-year OS was similar between patients with nodal metastases above and below the bifurcation of the common iliac vessels [45]. Since, three additional studies confirmed the lack of prognostic difference between common iliac and pelvic nodal metastases [46-48], justifying its N3 classification in the 7th AJCC staging system.

Taken together, surgeons performing RC-LND should aim to completely remove nodal tissue within the true pelvis and the common iliac templates up to the ureteral crossing. With thorough dissection, RC-LND consistently renders $29-39.4 \%$ of patients with $\mathrm{pN}+\mathrm{BCa}$ cancer free 5 years postoperatively. Patients with low nodal metastatic burden as well as organ confined primary disease seem to derive the most benefit from this procedure.

More controversially, adjuvant chemotherapy may also improve survival in $\mathrm{pN}+\mathrm{BCa}$ patients after $\mathrm{RC}$ LND. As the majority of recurrences occurred at distant sites, failure of cancer control was attributed to systemic disease spread [37]. In line with this, Madersbacher et al. found prolonged CSS in $\mathrm{pN}+$ patients receiving adjuvant chemotherapy $(21.5 \mathrm{mo}$ vs. $13.1 \mathrm{mo}$ ) [37]. This finding was corroborated in another study, in which adjuvant chemotherapy was found to reduce cancer specific mortality 2.1 fold $(p=0.005)$ [32]. In contrast, several earlier studies failed to demonstrate survival benefit in patients receiving adjuvant chemotherapy $[33,35]$. Different findings amongst these studies may be attributed to their smaller sample size or suboptimal chemotherapy regimen.

\section{INDEX PATIENT 3: CLINICAL NODE POSITIVE DISEASE}

After the emergence of level I evidence in support of using PSC prior to RC-LND [49, 50], a few studies investigated the role of combination therapy in treating the high risk MIBC patients with clinical nodal metastasis $(\mathrm{cN}+)$. A group from the Netherlands reported median CSS of 20 months and 5-year CSS in 29.2\% [51, 52]. In comparison, median CSS and 5-year CSS in the patients rendered disease free on the pathologic specimen after PSC (pCR) were 127 months and $63.5 \%$, respectively [51]. On multivariate analysis, pCR was found to be a significant predictor of CSS. In a smaller cohort, Ho et al. confirmed the important prognostic role of pCR, demonstrating 5 -year CSS in 83.3\% [53]. Notwithstanding its prognostic importance, pCR was found in just $14.5 \%$ of patients in a North American multi-institutional study consisting of $304 \mathrm{cN} 1-3 \mathrm{BCa}$ patients treated with combination therapy [54]. Surprisingly, $38 \%$ with CR at the primary tumor site (pT0) were found to have persistent metastatic LNs. Survival in patients with pCR were in line with previous findings. On multivariate analysis, surgical margin and nodal yield of at least 15 were found to be significant predictors of OS, underscoring the importance of complete surgical consolidation after PSC.

To further examine the value of consolidative RC-LND, two recent studies compared surgical resection and conservative management following chemotherapy for patients with $\mathrm{cN}+\mathrm{BCa}$. Necchi 
et al. demonstrated improved PFS and OS in patients undergoing consolidative surgical lymphadenectomy after achieving CR with chemotherapy [55]. However, these results were difficult to interpret as the cohort included both $\mathrm{cN}+$ patients on primary diagnosis as well as recurrence after RC-LND. Furthermore, the relatively small sample size consisted of both $\mathrm{cN}+\mathrm{BCa}$ and UTUC patients, arguably two distinct disease entities.

More convincing evidence emerged from an analysis of $1,104 \mathrm{cN}+\mathrm{BCa}$ patients within the National Cancer Data Base (NCDB) undergoing chemotherapy alone, cystectomy alone, PSC followed by RC-LND, and RC-LND followed by adjuvant chemotherapy [56]. While 5-year OS following chemotherapy (14\%; 95\% CI: $11-17 \%)$ and cystectomy (19\%; 95\% CI: 15-24\%) were similar, improvements were noted in patients undergoing combination PSC followed by RC-LND (31\%; 95\% CI: 25-38\%) and RC-LND followed by adjuvant chemotherapy (26\%; 95\% CI: 21-34\%). Although PSC increased pN0 rate 11.2 fold, the importance of salvage RC-LND was evidenced by the dramatic increase in OS in patients undergoing combination therapy (31\% 5-year OS) vs. chemotherapy alone (14\% 5-year OS). As acknowledged by the authors, frailty was not captured in the database, and may bias the results in favor of combination therapy.

\section{INDEX PATIENT 4: METASTATIC DISEASE}

Local treatment (LT) in the metastatic setting has gained prominence for a wide range of solid tumors [1-3]. Theoretically, this approach can limit disease progression by suppressing the source of tumor growth factors and new metastases as well as impact the patients' quality of life by eliminating the significant adverse effects brought on by local disease progression. For $\mathrm{BCa}$, evidence is limited to only a few retrospective reviews. The most compelling data supporting the utility of intensive LT for metastatic $\mathrm{BCa}$ was compiled from the NCDB [57]. Of 3,753 patients receiving systemic chemotherapy, 297 received high-intensity $\mathrm{LT}$, defined as $\mathrm{RC}$ or $\geq 50 \mathrm{~Gy}$ radiotherapy. The median OS was found to be significantly longer in patients receiving high-intensity LT than those receiving conservative LT (14.92 [IQR, 9.82 to 30.72 ] vs. 9.95 [IQR, 5.29 to 17.08 ] months, $p<0.001)$. Furthermore, the subgroup receiving consolidative surgery (i.e. RC after chemotherapy) achieved even higher OS than the high-intensity LT group overall (17.71 [IQR, 10.41 to not estimable] vs. 12.42 [IQR, 7.06 to 20.37] months, $p<0.001$ ).

These findings were corroborated by subgroup analyses from earlier post chemotherapy cystectomy series [58]. In small subgroups with clinical extraregional lymph node $(n=11)$ and visceral metastases $(n=9), 5$-year survival was achieved by $15 \%$. Not surprisingly, patients harboring visceral metastases fared worse than those with clinical lymph node metastases only after consolidative surgery.

RC may also be used towards palliating local symptoms brought on by disease progression, including bleeding, pain, dysuria and urinary obstruction. Of these, hematuria associated with bladder tumors causes significant morbidity and can be both difficult and expensive to treat. Invariably, some patients with intractable hematuria may require invasive procedures such as TURBT, urinary diversion, and ultimately RC. Having RC upfront may help avoid these unpleasant morbidities as well as the additional mortality risk associated with emergency surgery done in a desperation setting.

\section{Metastesectomy}

The role of metastatectomy for $\mathrm{mBCa}$ is controversial despite several retrospective reports demonstrating feasibility [59-64] (Table 2). As with any surgical procedure performed in the metastatic setting, patient selection is of paramount importance. In patients with heavy disease burden involving multiple organs, metastatectomy resulted in a dismal median OS of 7 months [63]. Moreover, asymptomatic patients prior to metastatectomy suffered a decrease in performance status as a result of the surgery. Although no formal selection criteria exists for metastatectomy, adherence to the following general principles may enhance efficacy: patients who demonstrated response to chemotherapy, recurrence in the initial or sole metastatic site, resectable tumors with clear margins, and a period of disease stability without progression (3 months) [64]. The small numbers in previous retrospective reviews on metastatectomy make it difficult to draw conclusions regarding the clinical characteristics predictive of treatment success $[61,64]$. However, several studies have suggested favorable prognosis for patients with solitary pulmonary metastases [59, 60, 62, 65]. Ultimately, prospective trials are needed to test the efficacy of not only surgical extirpation of the primary disease, but also of metastatic lesions elsewhere. 
Table 2

Metastasectomy

\begin{tabular}{|c|c|c|c|c|}
\hline Study (year) & $\begin{array}{c}\text { Number of } \\
\text { patients }\end{array}$ & Metastatic site & $\begin{array}{c}\% \text { with viable } \\
\text { tumors }\end{array}$ & Survival \\
\hline Miller (1993) & 36 & $\mathrm{n} / \mathrm{a}$ & $69.40 \%$ & $\begin{array}{l}3 \text { yr OS } 82 \% \text { for CR after chemo, } \\
46 \% \text { for CR after chemo+surgery }\end{array}$ \\
\hline Dodd (1999) & 50 & $\begin{array}{l}\text { Lymph nodes or abdominal/pelvic mass: } \\
\qquad n=32 \text {; lung: } n=10 \text {; bone: } n=3 \text {, liver: } n=1\end{array}$ & $66 \%$ & $\begin{array}{l}5 \text { yr OS } 41 \% \text { for CR after chemo, } \\
33 \% \text { for CR ater chemo+surgery }\end{array}$ \\
\hline Siefker-Radtke (2004) & 31 & $\begin{array}{l}\text { Lymph nodes: } n=4 \text {; lung } n=24 \text {; brain: } n=2 \text {; } \\
\text { subcutaneous metastasis: } n=1\end{array}$ & $94 \%$ & 5 yr OS $33 \%$ \\
\hline Lehmann (2009) & 44 & $\begin{array}{l}\text { Lymph nodes: } n=30 \text {; lung: } n=8 \text {; bone: } \\
\quad n=2 \text {; adrenal gland: } n=1 ; \text { brain } n=1 \\
\text { small intestine: } n=1 ; \text { subcutaneous } \\
\text { metastasis: } n=1\end{array}$ & $82 \%$ & 5 yr OS $28 \%$ \\
\hline Kanzaki (2010) & 18 & Lung: $n=18$ & $100 \%$ & 5 yr OS $46.5 \%$ \\
\hline Matsuguma (2011) & 32 & Lung: $n=32$ & $\mathrm{n} / \mathrm{a}$ & 5 yr OS $50 \%$ \\
\hline Abe (2014) & 42 & $\begin{array}{l}\text { Lymph node: } n=20 \text {; lung: } n=12 \text {; pelvic soft } \\
\text { tissue: } n=3 \text {; local recurrence } n=2 \text {; } \\
\text { subcutaneous metastases: } n=2 ; \text { liver: } \\
n=1 ; \text { others } n=2\end{array}$ & $71 \%$ & 5 yr OS $31 \%$ \\
\hline
\end{tabular}

\section{FEASIBILITY OF RADICAL}

\section{CYSTECTOMY IN PATIENTS WITH} METASTATIC BLADDER CANCER

Advanced local disease may often be encountered in the cytoreductive setting, adding complexity to surgical extirpation. Several studies have focused on the feasibility of $\mathrm{RC}$ in locally advanced, $\mathrm{T} 4 \mathrm{BCa}$ [66, 67]. In a series of 20 consecutive pT4 BCa patients undergoing RC, Nagele et al. found few perioperative complications, including insignificant pulmonary embolism and acute renal failure in one patient and an enterocutaneous fistula in another [67]. In another study, Moschini et al. found higher rate of transfusion and longer postoperative hospital stays for the cT4b patients, but perioperative complications as well as 30 day readmission rates were similar as those with cT1-3 UC [66]. Al-Daghmin recently evaluated the feasibility of robotic-assisted radical cystectomy (RARC) for patients with pT4 UC. While complication rates were similar, the 30- and 90-day mortalities were higher for pT4 patients than those with $\leq$ pT3 disease [68]. Furthermore, BMI has been found to be an independent predictor for postoperative complications [69]. Negative margin rates for T4 disease ranged from 74.4 to $91.1 \%$ [24, 26, 29, 66].

\section{IDENTIFYING APPROPRIATE CANDIDATES FOR CYTOREDUCTIVE SURGERY FOR RADICAL CYSTECTOMY, ROLE OF IMAGING.}

As no formal criteria exist, general oncologic principles may help guide in selecting candidates with metastatic BCa for RC-LND. At this time, it is felt that patients who are most likely to benefit from PSC followed by RC-LND are those that: demonstrated response to chemotherapy, have a minimal metastatic burden, have resectable tumors, and/or a period (3 months) in which disease stability has been demonstrated without progression [64]. In particular, retrospective studies have suggested prolonged survival in patients with oligometastatic LN or lung metastases after local control and even metastatectomy [59, 60, 62, 65]. In addition, host factors such as age, sex, and comorbidity as well as performance status may play vital roles in patient selection. Future advances in the understanding of the molecular mechanisms behind $\mathrm{BCa}$ oncogenesis may help to distinguish indolent from aggressive variants of $\mathrm{mBCa}$. For example, Kim et al. used next-generation sequencing to identify genomic subsets of highgrade $\mathrm{BCa}$ associated with favorable and unfavorable outcomes post RC [70]. Ultimately, the efficacy of aggressive surgical extirpation in the metastatic setting will need to be verified in well-designed prospective trials.

\section{CONCLUSION}

Surgical extirpation of the primary tumor may be an important component in the management of metastatic BCa. Existing retrospective data demonstrate efficacy in carefully selected patients, especially after favorable response to systemic chemotherapy. Surgical extirpation has been demonstrated to be feasible even with locally advanced disease in the post-chemo setting. Though highly 
morbid, perioperative outcomes after RC-LND have improved with the advent of minimally invasive surgery and enhanced postsurgical pathways. The time is ripe for well-designed, prospective, trials to test the efficacy of cystectomy for metastatic BCa.

\section{REFERENCES}

[1] Bristow RE, Tomacruz RS, Armstrong DK, Trimble EL, Montz FJ. Survival effect of maximal cytoreductive surgery for advanced ovarian carcinoma during the platinum era: A meta-analysis. Journal of Clinical Oncology: Official Journal of the American Society of Clinical Oncology 2002;20(5):1248-59.

[2] Flanigan RC, Salmon SE, Blumenstein BA, Bearman SI, Roy V, McGrath PC, et al. Nephrectomy followed by interferon alfa-2b compared with interferon alfa- $2 b$ alone for metastatic renal-cell cancer. The New England Journal of Medicine 2001;345(23):1655-9.

[3] Löppenberg B, Dalela D, Karabon P, Sood A, Sammon JD, Meyer CP, et al. The Impact of Local Treatment on Overall Survival in Patients with Metastatic Prostate Cancer on Diagnosis: A National Cancer Data Base Analysis. European Urology.

[4] Dimopoulos MA, Finn L, Logothetis CJ. Pattern of failure and survival of patients with metastatic urothelial tumors relapsing after cis-platinum-based chemotherapy. The Journal of Urology 1994;151(3):598-600; discussion -1.

[5] Alfred Witjes J, Lebret T, Comperat EM, Cowan NC, De Santis M, Bruins HM, et al. Updated 2016 EAU Guidelines on Muscle-invasive and Metastatic Bladder Cancer. Eur Urol 2017;71(3):462-75.

[6] Stein JP, Lieskovsky G, Cote R, Groshen S, Feng AC, Boyd $\mathrm{S}$, et al. Radical cystectomy in the treatment of invasive bladder cancer: Long-term results in 1,054 patients. Journal of Clinical Oncology: Official Journal of the American Society of Clinical Oncology 2001;19(3):666-75.

[7] Novotny V, Hakenberg OW, Wiessner D, Heberling U, Litz RJ, Oehlschlaeger S, et al. Perioperative complications of radical cystectomy in a contemporary series. Eur Urol 2007;51(2):397-401; discussion -2.

[8] Stimson CJ, Chang SS, Barocas DA, Humphrey JE, Patel SG, Clark PE, et al. Early and late perioperative outcomes following radical cystectomy: 90-day readmissions, morbidity and mortality in a contemporary series. The Journal of Urology 2010;184(4):1296-300.

[9] Shabsigh A, Korets R, Vora KC, Brooks CM, Cronin AM, Savage C, et al. Defining early morbidity of radical cystectomy for patients with bladder cancer using a standardized reporting methodology. Eur Urol 2009;55(1):164-74.

[10] Yuh B, Wilson T, Bochner B, Chan K, Palou J, Stenzl A, et al. Systematic review and cumulative analysis of oncologic and functional outcomes after robot-assisted radical cystectomy. Eur Urol 2015;67(3):402-22.

[11] S.B. Edge DRB, C.C. Compton, et al. AJCC Cancer Staging Manual (7th Ed.), Springer, New York 2010.

[12] Loehrer PJ, Sr., Einhorn LH, Elson PJ, Crawford ED, Kuebler P, Tannock I, et al. A randomized comparison of cisplatin alone or in combination with methotrexate, vinblastine, and doxorubicin in patients with metastatic urothelial carcinoma: A cooperative group study. Journal of Clinical Oncology: Official Journal of the American Society of Clinical Oncology 1992;10(7):1066-73.
[13] von der Maase H, Hansen SW, Roberts JT, Dogliotti L, Oliver T, Moore MJ, et al. Gemcitabine and cisplatin versus methotrexate, vinblastine, doxorubicin, and cisplatin in advanced or metastatic bladder cancer: Results of a large, randomized, multinational, multicenter, phase III study. Journal of Clinical Oncology: Official Journal of the American Society of Clinical Oncology 2000;18(17): 3068-77.

[14] Logothetis CJ, Dexeus FH, Finn L, Sella A, Amato RJ, Ayala AG, et al. A prospective randomized trial comparing MVAC and CISCA chemotherapy for patients with metastatic urothelial tumors. Journal of Clinical Oncology: Official Journal of the American Society of Clinical Oncology 1990;8(6):1050-5.

[15] Bellmunt J, Theodore C, Demkov T, Komyakov B, Sengelov L, Daugaard G, et al. Phase III trial of vinflunine plus best supportive care compared with best supportive care alone after a platinum-containing regimen in patients with advanced transitional cell carcinoma of the urothelial tract. Journal of Clinical Oncology: Official Journal of the American Society of Clinical Oncology 2009;27(27): 4454-61.

[16] Balar AV. Immune Checkpoint Blockade in Metastatic Urothelial Cancer. Journal of Clinical Oncology: Official Journal of the American Society of Clinical Oncology 2017;35(19):2109-12.

[17] Ghahestani SM, Shakhssalim N. Palliative treatment of intractable hematuria in context of advanced bladder cancer: A systematic review. Urology Journal 2009;6(3):149-56.

[18] Zebic N, Weinknecht S, Kroepfl D. Radical cystectomy in patients aged>or $=75$ years: An updated review of patients treated with curative and palliative intent. BJU International 2005;95(9):1211-4.

[19] Shariat SF, Palapattu GS, Karakiewicz PI, Rogers CG, Vazina A, Bastian PJ, et al. Discrepancy between clinical and pathologic stage: Impact on prognosis after radical cystectomy. Eur Urol 2007;51(1):137-49; discussion 49-51.

[20] Kundra V, Silverman PM. Imaging in oncology from the University of Texas M. D. Anderson Cancer Center. Imaging in the diagnosis, staging, and follow-up of cancer of the urinary bladder. AJR American Journal of Roentgenology 2003;180(4):1045-54.

[21] Baltaci S, Resorlu B, Yagci C, Turkolmez K, Gogus C, Beduk Y. Computerized tomography for detecting perivesical infiltration and lymph node metastasis in invasive bladder carcinoma. Urologia Internationalis 2008;81(4):399-402.

[22] Vargas HA, Akin O, Schoder H, Olgac S, Dalbagni G, Hricak H, et al. Prospective evaluation of MRI, (1)(1)C-acetate PET/CT and contrast-enhanced CT for staging of bladder cancer. European Journal of Radiology 2012;81(12): 4131-7.

[23] Culp SH, Dickstein RJ, Grossman HB, Pretzsch SM, Porten S, Daneshmand S, et al. Refining patient selection for neoadjuvant chemotherapy before radical cystectomy. The Journal of Urology 2014;191(1):40-7.

[24] Furukawa J, Miyake H, Hara I, Takenaka A, Fujisawa M. Clinical outcome of radical cystectomy for patients with pT4 bladder cancer. International Journal of Urology: Official Journal of the Japanese Urological Association 2008;15(1):58-61.

[25] Liberman D, Alasker A, Sun M, Ismail S, Lughezzani G, Jeldres C, et al. Radical cystectomy for patients with pT4 urothelial carcinoma in a large population-based study. BJU International 2011;107(6):905-11. 
[26] Tilki D, Svatek RS, Karakiewicz PI, Isbarn H, Reich O, Kassouf W, et al. Characteristics and outcomes of patients with pT4 urothelial carcinoma at radical cystectomy: A retrospective international study of 583 patients. The Journal of Urology 2010;183(1):87-93.

[27] Fossa SD, Sternberg C, Scher HI, Theodore CH, Mead B, Dearnaley D, et al. Survival of patients with advanced urothelial cancer treated with cisplatin-based chemotherapy. British Journal of Cancer 1996;74(10):1655-9.

[28] Herr HW, Donat SM, Bajorin DF. Post-chemotherapy surgery in patients with unresectable or regionally metastatic bladder cancer. The Journal of Urology 2001; 165(3):811-4.

[29] Black PC, Dinney CP, Brown GA, Kassouf W, SiefkerRadtke AO, Munsell MF, et al. The role of radical cystectomy in patients with clinical T4b bladder cancer. Urologic Oncology 2011;29(2):157-61.

[30] Skinner DG. Management of Invasive Bladder Cancer: A Meticulous Pelvic Node Dissection Can Make a Difference. The Journal of Urology 128(1):34-6.

[31] Aprikian A, Atef A, Duguid W, Bazinet M, Laplante M, Reid E, et al. Survival after pelvic lymphadenectomy and radical cystectomy in patients with lymph-node metastatic transitional-cell carcinoma of the bladder. Oncology Reports 1995;2(4):633-5.

[32] Frank I, Cheville JC, Blute ML, Lohse CM, Nehra A, Weaver AL, et al. Transitional cell carcinoma of the urinary bladder with regional lymph node involvement treated by cystectomy: Clinicopathologic features associated with outcome. Cancer 2003;97(10):2425-31.

[33] Lerner SP, Skinner DG, Lieskovsky G, Boyd SD, Groshen SL, Ziogas A, et al. The rationale for en bloc pelvic lymph node dissection for bladder cancer patients with nodal metastases: Long-term results. The Journal of Urology 1993;149(4):758-64; discussion 64-5.

[34] Mills RD, Turner WH, Fleischmann A, Markwalder R, Thalmann GN, Studer UE. Pelvic lymph node metastases from bladder cancer: Outcome in 83 patients after radical cystectomy and pelvic lymphadenectomy. The Journal of Urology 2001;166(1):19-23.

[35] Vieweg J, Gschwend JE, Herr HW, Fair WR. Pelvic lymph node dissection can be curative in patients with node positive bladder cancer. The Journal of Urology 1999;161(2): 449-54.

[36] Hautmann RE, de Petriconi RC, Pfeiffer C, Volkmer BG. Radical cystectomy for urothelial carcinoma of the bladder without neoadjuvant or adjuvant therapy: Long-term results in 1100 patients. Eur Urol 2012;61(5):1039-47.

[37] Madersbacher S, Hochreiter W, Burkhard F, Thalmann GN, Danuser H, Markwalder R, et al. Radical cystectomy for bladder cancer today-a homogeneous series without neoadjuvant therapy. Journal of Clinical Oncology: Official Journal of the American Society of Clinical Oncology 2003;21(4):690-6.

[38] Stein JP, Cai J, Groshen S, Skinner DG. Risk factors for patients with pelvic lymph node metastases following radical cystectomy with en bloc pelvic lymphadenectomy: Concept of lymph node density. The Journal of Urology 2003;170(1):35-41.

[39] Leissner J, Hohenfellner R, Thuroff JW, Wolf HK. Lymphadenectomy in patients with transitional cell carcinoma of the urinary bladder; significance for staging and prognosis. BJU Int 2000;85(7):817-23.

[40] Herr HW, Bochner BH, Dalbagni G, Donat SM, Reuter VE, Bajorin DF. Impact of the number of lymph nodes retrieved on outcome in patients with muscle invasive bladder cancer. J Urol 2002;167(3):1295-8.

[41] Herr HW, Faulkner JR, Grossman HB, Natale RB, deVere White R, Sarosdy MF, et al. Surgical factors influence bladder cancer outcomes: A cooperative group report. J Clin Oncol 2004;22(14):2781-9.

[42] Kassouf W, Leibovici D, Munsell MF, Dinney CP, Grossman HB, Kamat AM. Evaluation of the relevance of lymph node density in a contemporary series of patients undergoing radical cystectomy. The Journal of Urology 2006;176(1): 53-7; discussion 7.

[43] Dhar NB, Klein EA, Reuther AM, Thalmann GN, Madersbacher S, Studer UE. Outcome After Radical Cystectomy with Limited or Extended Pelvic Lymph Node Dissection. The Journal of Urology 2008;179(3):873-8.

[44] Zehnder P, Studer UE, Skinner EC, Dorin RP, Cai J, Roth $\mathrm{B}$, et al. Super extended versus extended pelvic lymph node dissection in patients undergoing radical cystectomy for bladder cancer: A comparative study. The Journal of Urology 2011;186(4):1261-8.

[45] Steven K, Poulsen AL. Radical cystectomy and extended pelvic lymphadenectomy: Survival of patients with lymph node metastasis above the bifurcation of the common iliac vessels treated with surgery only. The Journal of Urology 2007;178(4 Pt 1):1218-23; discussion 23-4.

[46] Bruins HM, Dorin RP, Rubino B, Miranda G, Cai J, Daneshmand S, et al. Critical evaluation of the American Joint Committee on Cancer TNM nodal staging system in patients with lymph node-positive disease after radical cystectomy. Eur Urol 2012;62(4):671-6.

[47] Jensen JB, Ulhoi BP, Jensen KM. Evaluation of different lymph node $(\mathrm{LN})$ variables as prognostic markers in patients undergoing radical cystectomy and extended LN dissection to the level of the inferior mesenteric artery. BJU International 2012;109(3):388-93.

[48] Tarin TV, Power NE, Ehdaie B, Sfakianos JP, Silberstein JL, Savage CJ, et al. Lymph node-positive bladder cancer treated with radical cystectomy and lymphadenectomy: Effect of the level of node positivity. Eur Urol 2012;61(5):1025-30.

[49] Neoadjuvant chemotherapy in invasive bladder cancer: Update of a systematic review and meta-analysis of individual patient data advanced bladder cancer $(\mathrm{ABC})$ meta-analysis collaboration. Eur Urol 2005;48(2):202-5; discussion 5-6.

[50] Grossman HB, Natale RB, Tangen CM, Speights VO, Vogelzang NJ, Trump DL, et al. Neoadjuvant chemotherapy plus cystectomy compared with cystectomy alone for locally advanced bladder cancer. The New England Journal of Medicine 2003;349(9):859-66.

[51] Meijer RP, Mertens LS, van Rhijn BW, Bex A, van der Poel HG, Meinhardt W, et al. Induction chemotherapy followed by surgery in node positive bladder cancer. Urology 2014;83(1):134-9.

[52] Nieuwenhuijzen JA, Bex A, Meinhardt W, Kerst JM, Schornagel JH, H VANT, et al. Neoadjuvant methotrexate, vinblastine, doxorubicin and cisplatin for histologically proven lymph node positive bladder cancer. The Journal of Urology 2005;174(1):80-5.

[53] Ho PL, Willis DL, Patil J, Xiao L, Williams SB, Melquist JJ, et al. Outcome of patients with clinically nodepositive bladder cancer undergoing consolidative surgery after preoperative chemotherapy: The M.D. Anderson Cancer Center Experience. Urologic Oncology 2016;34(2): 59.e1-8. 
[54] Zargar-Shoshtari K, Zargar H, Lotan Y, Shah JB, van Rhijn BW, Daneshmand S, et al. A Multi-Institutional Analysis of Outcomes of Patients with Clinically Node Positive Urothelial Bladder Cancer Treated with Induction Chemotherapy and Radical Cystectomy. The Journal of Urology 2016;195(1):53-9.

[55] Necchi A, Giannatempo P, Lo Vullo S, Fare E, Raggi D, Nicolai N, et al. Postchemotherapy lymphadenectomy in patients with metastatic urothelial carcinoma: Long-term efficacy and implications for trial design. Clinical Genitourinary Cancer 2015;13(1):80-6.e1.

[56] Galsky MD, Stensland K, Sfakianos JP, Mehrazin R, Diefenbach M, Mohamed N, et al. Comparative Effectiveness of Treatment Strategies for Bladder Cancer With Clinical Evidence of Regional Lymph Node Involvement. Journal of Clinical Oncology: Official Journal of the American Society of Clinical Oncology 2016;34(22):2627-35.

[57] Seisen T, Sun M, Leow JJ, Preston MA, Cole AP, GelpiHammerschmidt F, et al. Efficacy of High-Intensity Local Treatment for Metastatic Urothelial Carcinoma of the Bladder: A Propensity Score-Weighted Analysis From the National Cancer Data Base. Journal of Clinical Oncology: Official Journal of the American Society of Clinical Oncology 2016.

[58] Dodd PM, McCaffrey JA, Herr H, Mazumdar M, Bacik J, Higgins G, et al. Outcome of postchemotherapy surgery after treatment with methotrexate, vinblastine, doxorubicin, and cisplatin in patients with unresectable or metastatic transitional cell carcinoma. J Clin Oncol 1999;17(8):2546-52.

[59] Abe T, Kitamura H, Obara W, Matsumura N, Tsukamoto $\mathrm{T}$, Fujioka T, et al. Outcome of metastasectomy for urothelial carcinoma: A multi-institutional retrospective study in Japan. The Journal of Urology 2014;191(4):932-6.

[60] Kanzaki R, Higashiyama M, Fujiwara A, Tokunaga T, Maeda J, Okami J, et al. Outcome of surgical resection of pulmonary metastasis from urinary tract transitional cell carcinoma. Interactive Cardiovascular and Thoracic Surgery 2010;11(1):60-4.

[61] Lehmann J, Suttmann H, Albers P, Volkmer B, Gschwend JE, Fechner G, et al. Surgery for metastatic urothelial carcinoma with curative intent: The German experience (AUO AB 30/05). Eur Urol 2009;55(6):1293-9.
[62] Matsuguma H, Yoshino I, Ito H, Goya T, Matsui Y, Nakajima $\mathrm{J}$, et al. Is there a role for pulmonary metastasectomy with a curative intent in patients with metastatic urinary transitional cell carcinoma? The Annals of Thoracic Surgery 2011;92(2):449-53.

[63] Otto T, Krege S, Suhr J, Rubben H. Impact of surgical resection of bladder cancer metastases refractory to systemic therapy on performance score: A phase II trial. Urology 2001;57(1):55-9.

[64] Siefker-Radtke AO, Walsh GL, Pisters LL, Shen Y, Swanson DA, Logothetis CJ, et al. Is there a role for surgery in the management of metastatic urothelial cancer? The M. D. Anderson experience. The Journal of Urology 2004;171(1):145-8.

[65] Cowles RS, Johnson DE, McMurtrey MJ. Long-term results following thoracotomy for metastatic bladder cancer. Urology 1982;20(4):390-2.

[66] Moschini M, Luzzago S, Zaffuto E, Dell' Oglio P, Gandaglia $\mathrm{G}$, Mattei A, et al. The surgical management of patients with clinical stage T4 bladder cancer: A single institution experience. European Journal of Surgical Oncology (EJSO).

[67] Nagele U, Anastasiadis AG, Merseburger AS, Corvin S, Hennenlotter J, Adam M, et al. The rationale for radical cystectomy as primary therapy for T4 bladder cancer. World Journal of Urology 2007;25(4):401-5.

[68] Al-Daghmin A, Kauffman EC, Shi Y, Badani K, Balbay MD, Canda E, et al. Efficacy of robot-assisted radical cystectomy (RARC) in advanced bladder cancer: Results from the International Radical Cystectomy Consortium (IRCC). BJU International 2014;114(1):98-103.

[69] Moschini M, Luzzago S, Zaffuto E, Dell'Oglio P, Gandaglia $\mathrm{G}$, Mattei A, et al. The surgical management of patients with clinical stage T4 bladder cancer: A single institution experience. European Journal of Surgical Oncology: The Journal of the European Society of Surgical Oncology and the British Association of Surgical Oncology 2017;43(4): 808-14.

[70] Kim PH, Cha EK, Sfakianos JP, Iyer G, Zabor EC, Scott $\mathrm{SN}$, et al. Genomic predictors of survival in patients with high-grade urothelial carcinoma of the bladder. Eur Urol 2015;67(2):198-201. 